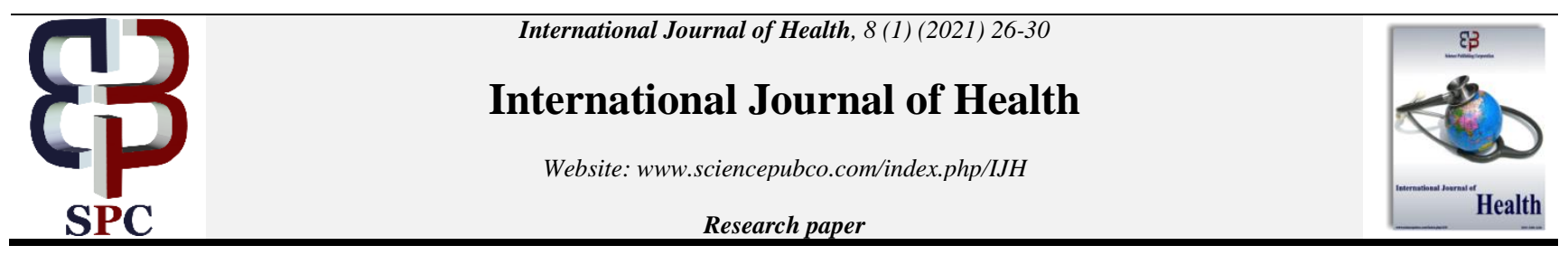

\title{
Effectiveness of teacher-based nutrition interventions in addressing malnutrition among sub-Saharan children
}

\author{
Jonathan Nsamba * \\ Master of Public Health- Health Promotion graduate, Uganda Martyrs University. P.O. Box 5498 Kampala \\ *Corresponding author E-mail: jonathan.nsamba@stud.umu.ac.ug
}

\begin{abstract}
Introduction: To address the high malnutrition rates in Sub Saharan Africa, most programs addressing malnutrition have continuously been streamlined through the health system, yet this has not yielded results as expected. On the other hand, the education sector has shown an immense capacity to address some challenges, such as eliminating short-term hunger through School feeding programs. Yet, little attention has been given to teachers as far as implementing health and nutrition interventions. With an increased school enrolment rate in Sub Saharan Africa, teachers present huge potential as change agents.

Objectives: To consolidate evidence about the effectiveness of teacher-based interventions in addressing malnutrition in Sub- Saharan Africa.

Methods: A search strategy through online databases including EBSCO, PubMed, BASE, Cochrane, Google Scholar, LILACS, Project MUSE, TRIP Database, and Emerald Insight gave rise to 95,734 studies. These were identified and taken through a series of screening stages such that the most eligible were included to answer the review question.

Results: Three studies fulfilled the inclusion criteria. Results showed that teacher-based interventions such as school lunch, deworming, vitamin A supplementation, and nutrition education positively affect the nutrition status of primary school children, school attendances, are sustainable and reach many children.

Conclusion: There is a need to actively involve teachers in the primordial and primary prevention stages of malnutrition through strengthening nutrition education, supplementary programs and school gardening. Teachers have an essential role to play in the fight against Malnutrition in Sub Saharan Africa.
\end{abstract}

Keywords: Malnutrition; Sub-Saharan Africa; School; Teachers.

\section{Introduction}

A growing body of evidence suggests an existence of a double burden of malnutrition characterised by under and over nutrition existing concurrently among Sub- Saharan primary school children [1]. Many nutrition-specific and sensitive interventions [2] continue to be implemented in the region to address this double burden. These are mainly streamlined through the health sector, albeit yielding minimal short-term successes as far as improving nutrition indicators is concerned despite the enormous financial inputs. Does this call for a permutation of approach to involve school teachers?

The African region has remained the global hotspot for hunger and malnutrition. The number of stunted children increased by about one third between 2000 and 2015, and 23 million children still attend school hungry [3]. Malnutrition undermines physical and intellectual growth and development [4] and contributes to more than one-third of all child mortality cases [5]. Yet, countries in Sub- Sahara have failed to effectively address malnutrition partly owed to lack of well tested integrated approaches in nutrition programming [6]

Addressing malnutrition in Sub- Saharan Africa requires a multi-sectoral approach involving various sectors such as health, education, agriculture, gender and social development, trade and industry, water and sanitation, among others [7] The rationale for a multi-sectoral approach arises from the recognition that prevention and management of malnutrition requires a synergy of an integrated response to break its vicious cycle [3]. The education sector has demonstrated immense capacity in addressing hunger and malnutrition through various approaches such as school feeding programs, school gardens, health and nutrition education.

Compelling evidence suggests that nutrition, health, and education are inextricably inter- linked since proper nutrition leads to healthy children attending school who achieve better grades at school, which is associated with improved health later in life [8]. Schools, therefore, offer an established network, broad channel, effective and an equal opportunity setting and platform for imparting nutrition knowledge in many children whose life stage is formative and influential in growth and development [1]. The formative stage is a critical stage of development during which lifestyles such as eating patterns are developed, tested and adopted through social interactions within the school. Therefore, teachers in educational institutions are not only agents of knowledge but also investments in health. Teachers can have an invaluable influence on the overall well-being of children, including their nutrition status, because of the considerable amount of time they spend together and the vast array of knowledge they impart to these children [9]. In Sub Saharan Africa, where malnutrition rates are 
deplorably high, their roles cannot be overemphasised. Thus, there is a need to explore teachers' feasibility as alternative channels for addressing the persistent determinants of malnutrition in Sub- Saharan Africa.

\section{Methods}

The search of electronic databases and search engines was undertaken to find relevant papers pertaining to the review question and that were published in any Sub-Saharan country between 2000- 2015. The Medical Subject Headings aided in the search strategy. Words such as "Food habit", "nutritional status", "child", "food", "knowledge", "bodyweight", "school", "school children" were used.

\subsection{Eligibility criteria}

The eligibility of studies to be considered for this review included studies published between 2000 and 2015. This time frame was considered because it marked the exponential increase in school enrolment of children as a result of the Millennium Development Goals.

\subsection{Inclusion and exclusion criteria}

\subsubsection{Inclusion criteria}

i) Intervention: Only three teacher-based nutrition interventions were considered; nutrition education, school feeding programs and school gardening because they are nutrition-specific.

ii) Geographical location: studies conducted in any country of Sub- Saharan Africa as classified by the World Bank.

iii) Population: studies carried out targeting School children- boys and girls in either single or mixed schools located in urban or rural settings.

iv) Study design: Only Randomised Controlled Trials and quasi-experimental studies were considered for this review. Studies that compared before and after the intervention strategy were included (pre-post).

v) Sample size: Studies that were carried out in more than one school.

vi) Language: Only English Language articles were eligible for inclusion

vii) Outcomes: Studies that were included should have reported nutrition anthropometry- wasting, stunting, and underweight, nutrition knowledge, program participants, cost-effectiveness, and contextual factors such as sustainability.

\subsubsection{Exclusion criteria}

Non-English publications, papers from the same country, duplicates found in online sources searched, uncontrolled before-and-after studies, case series, case reports, editorials, and case-control studies

\subsection{Primary outcomes}

Studies were included if they reported at least one of the following nutrition outcome measurements; anthropometry (Stunting, wasting and underweight, nutrition knowledge, dietary diversity, Mid Upper Arm Circumference, Vitamin A status, Iron status, food choices, dietary diversity, program participants, program cost evaluation and general quality of life.

\subsection{Literature search}

The goal of the literature search was to be exhaustive in acquiring a vast pool of relevant studies from which the most appropriate for the question would be selected. Databases such as EBSCO, Cochrane library, TRIP BASE, Emerald, Google Scholar, EMBASE, Project Muse, PubMed and LILACS were searched. Pearling was carried out where the reference lists of included studies were examined for potentially relevant studies not captured by the search. Then, their references were reviewed until a saturation point was reached.

\subsection{Quality assessment}

The reliability and validity of papers were appraised using the Evidence-Based Leadership checklist by Lindsay Glynn (10) to ensure that high-quality articles were included in the review. The quality of randomised controlled studies was further appraised using a five-point oxford quality rating scale- Jadad scale (11).

\subsubsection{Risk of bias}

The quality of reviewed papers was appraised using Cochrane's Collaboration tool for assessing the risk of bias.

\subsection{Data extraction}

The data extraction process followed the Cochrane Public Health Group data extraction and assessment template for intervention reviews. The extracted data included general information such as journal, title, author, volume, pages, objectives, type of trial, demographics of the study population, description of the intervention, description of the control group, results of the interventions, how they were measured and the country setting from which the study was carried out.

\subsection{Data analysis}

A mixed evaluation of studies was undertaken, and this study used the Evidence for Policy and Practice Information and Coordination Centre approach for data analysis. The study employed a random-effects model since this assumes different treatment effects and accounts for design and outcome variables variance. Meta-analysis was performed using the Comprehensive Meta-analysis software. Statistical 
heterogeneity was assessed via visual inspection of forest plots of the included trials. Examination of the trial characteristics such as participants, design, interventions and outcomes were also performed to identify the source of heterogeneity.

\section{Findings}

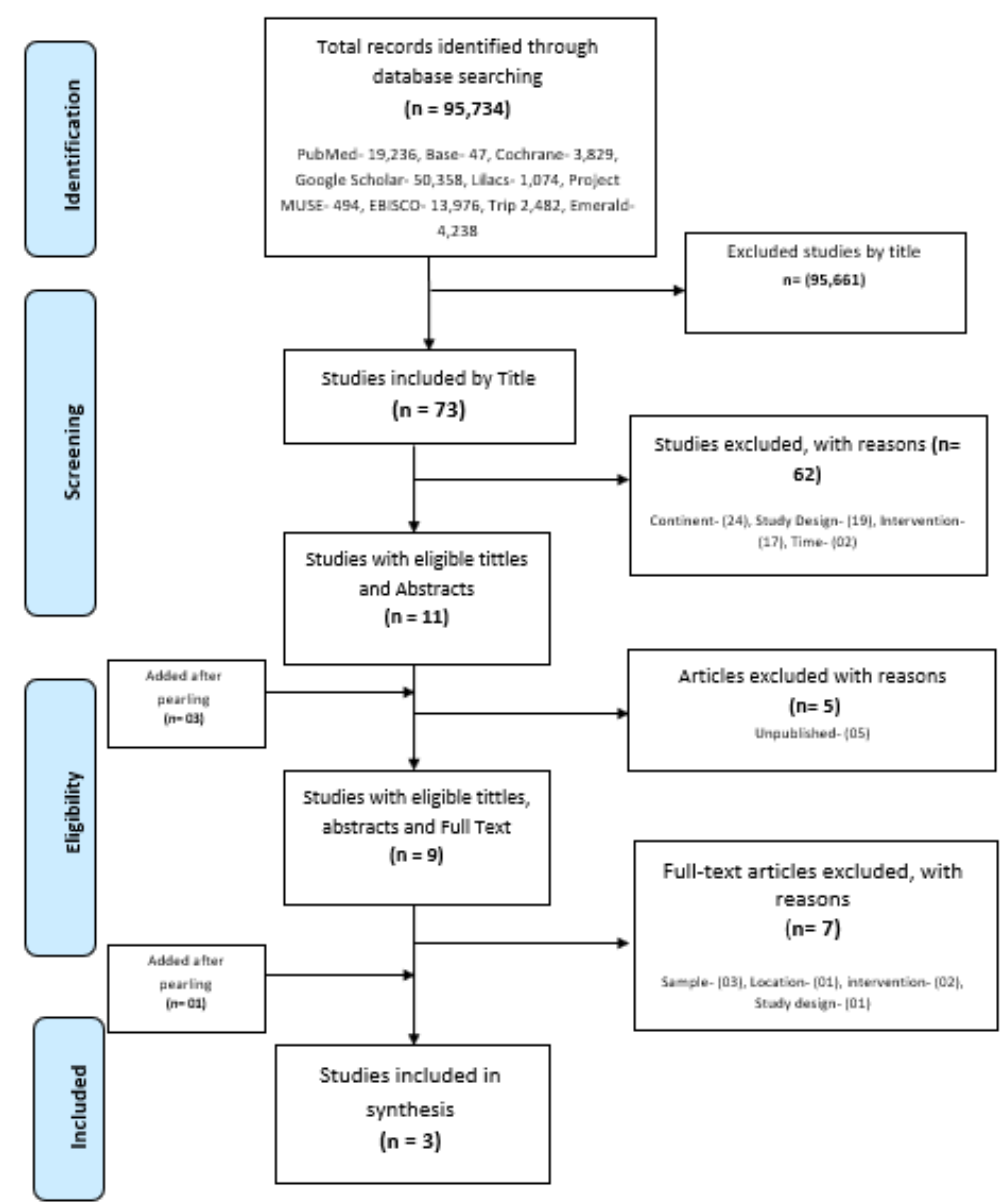

Fig. 1: Showing the PRISMA Flow Diagram.

\subsection{Study characteristics}

The studies that met the inclusion criteria were three. Two were Quasi-Experimental designs, whereas one was a Randomised Controlled Trial.

Table 1: Showing Details of Included Studies

\begin{tabular}{llllll}
\hline Author \& year & $\begin{array}{l}\text { Study De- } \\
\text { sign }\end{array}$ & Purpose & Findings & Gaps & Recommendation \\
\hline $\begin{array}{l}\text { (Steyn et al., } \\
\text { 2015) }\end{array}$ & $\begin{array}{l}\text { Cluster- } \\
\text { RCT }\end{array}$ & $\begin{array}{l}\text { Nutrition education and } \\
\text { make healthier food choices }\end{array}$ & Dietary diversity & $\begin{array}{l}\text { The setting } \\
\text { used }\end{array}$ & $\begin{array}{l}\text { Strengthen and implement the School } \\
\text { Nutrition Policy }\end{array}$ \\
$\begin{array}{l}\text { Eboh and } \\
\text { Boye, 2006) }\end{array}$ & $\begin{array}{l}\text { Quasi-Ex- } \\
\text { perimental }\end{array}$ & $\begin{array}{l}\text { Effect of school nutrition ed- } \\
\text { ucation }\end{array}$ & $\begin{array}{l}\text { Nutrition education and } \\
\text { food choices }\end{array}$ & $\begin{array}{l}\text { Inconsist- } \\
\text { encies }\end{array}$ & $\begin{array}{l}\text { Structured and unstructured integration } \\
\text { of nutrition within the school curriculum }\end{array}$ \\
$2008)$ & puasi-Ex- & To address the knowledge & Nutrition knowledge im- & Purposive & Widen nutrition education scope \\
proved significantly & sampling & Establish school gardens & \\
\hline
\end{tabular}

All the three studies included in this review met the validity of $\geq 75 \%$ as per the Evidence-Based Leadership Critical appraisal checklist. This ensured that high-quality papers were included in the review.

\subsection{Meta-analysis}

\section{Effect of Teacher- Based Interventions}

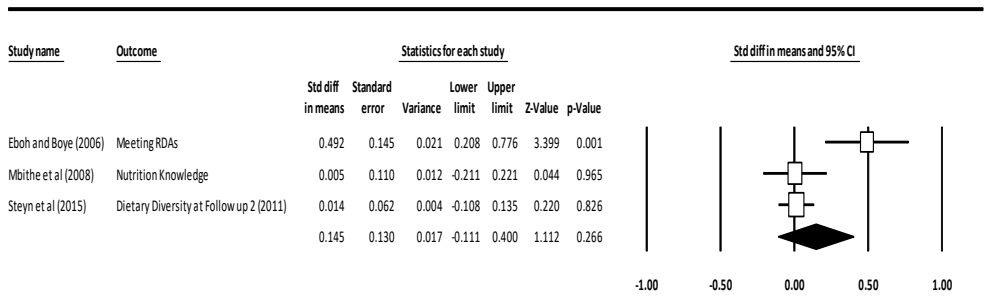

Fig. 2: Forest Plot Showing the Pooled Effect Size. 
The quantitative synthesis was undertaken to calculate the effect sizes of pooled studies.

The squares represent the point estimates of each study and are of different sizes because of the differences in study weights in terms of sample sizes and variance. The diamond is the pooled summary effect, and it is evident that the interventions positively favour improved dietary diversity and nutrition knowledge. The result is, however, weak $(0.145)$ at $95 \%$ CI. The mean differences between the control and intervention arms were used to estimate the pooled standardised mean difference in weight gained between intervention and control groups, using a random-effects model to account for variance in study design and outcome variables.

This was used because the reviewer assumed that the actual effects in the individual studies might be different from each other due to differing study designs and populations. The random-effects model provided a weighted average to individual studies since larger sample sizes decrease variability and increase precision.

To correct the effect of sample size on the effect measure, a hedge's G statistic was calculated whereby the standardised mean difference is divided by the pooled standard deviation. The random-effects model yielded a pooled Hedges $\mathrm{G}=0.145$ (95\% CI - $0.110-0.399$ ), showing a weak positive effect. The positive direction of Hedges $\mathrm{G}$ also indicates that the interventions favoured the outcomes.

Since this review brought together three studies carried out differently, there was a need to calculate heterogeneity. Statistical heterogeneity between trials was assessed using the $\mathrm{I}^{2}$ statistic. The Cochrane $\mathrm{I}^{2}$ interpretation used in this review was $25-<50$ Low heterogeneity, 50- $<$ $75 \%$ moderate and $>75 \%$ high heterogeneity. From the table below, the $\mathrm{I}^{2}$ is 79.315 showing a high heterogeneity among the studies owing to the different designs.

Table 2: Showing Summary Statistics

\begin{tabular}{|c|c|c|c|c|c|c|c|c|c|c|c|}
\hline \multicolumn{6}{|c|}{ Effect Size and 95\% Confidence Interval } & \multicolumn{2}{|c|}{$\begin{array}{l}\text { Test of Null (2- } \\
\text { tail) }\end{array}$} & \multicolumn{4}{|c|}{ Heterogeneity } \\
\hline $\begin{array}{l}\text { Number of } \\
\text { studies }\end{array}$ & $\begin{array}{l}\text { Point Esti- } \\
\text { mate }\end{array}$ & $\begin{array}{l}\text { Standard } \\
\text { Error }\end{array}$ & $\begin{array}{l}\text { Vari- } \\
\text { ance }\end{array}$ & $\begin{array}{l}\text { Lower } \\
\text { Limit }\end{array}$ & $\begin{array}{l}\text { Upper } \\
\text { Limit }\end{array}$ & $\begin{array}{l}\text { Z- } \\
\text { Value }\end{array}$ & $\begin{array}{l}\text { P- } \\
\text { Value }\end{array}$ & $\begin{array}{l}\text { Q- } \\
\text { Value }\end{array}$ & $\begin{array}{l}\text { Df } \\
(\mathrm{Q})\end{array}$ & $\begin{array}{l}\text { p- } \\
\text { Value }\end{array}$ & $\mathrm{I}^{2}$ \\
\hline 3 & 0.145 & 0.130 & 0.017 & -0.110 & 0.399 & 1.122 & 0.266 & 9.669 & 2 & 0.008 & 79.315 \\
\hline
\end{tabular}

A sensitivity analysis was performed by removing one study, and the effect did not change the overall effect. The pooled estimate remained $>0$, showing that the interventions still favoured the outcome positively. However, conducting a Meta-analysis did not overcome problems and challenges in the design and execution of the included primary studies, such as lack of randomisation of study participants and the short duration of interventions.

\section{Discussion}

The synthesised body of evidence shows weak evidence for the effectiveness of teacher-based interventions partly owed to the lack of robust primary randomised controlled trials. However, nutrition interventions in schools play a significant role in improving primary school children's nutrition and health status in Sub Saharan Africa.

Teacher-based interventions demonstrated that they are effective in the improvement of the nutrition status of children. A study by Mbithe (12) resulted in the reduction of underweight, stunting and wasting, and similar results were evidenced by Eboh and Boye (13). The interventions increased children's nutrition knowledge, which was transferred into adopting healthy nutrition practices. Similarly, one of the studies by Steyn (14) reported an improvement (36\%) in children's dietary diversity in the intervention arm. These results were similar to other studies $(15,16)$ who further provide more evidence about the roles teachers play in improving malnutrition among school children. The three studies (12-14) demonstrated the need for teachers to be involved as change agents. Bandura's social learning theory (17) recognises the significant opportunity for teachers if they are suitable role models. School children can emulate them and apply the same lifestyles, knowledge and skills for their growth and development.

Results from the reviewed studies showed that teacher-based interventions are sustainable if implemented correctly. A study by Mbithe (12) reported that new crops were transferred to the community by pupils after the study period. This showed continuity of the intervention, and these crops the community adopted were good sources of nourishment to households.

Lessons show that teachers could deliver nutrition interventions when they received adequate training and empowerment (14). However, the training should be accompanied by good monitoring and evaluation as a way of support supervision.

Studies (12-14) showed that teacher-based nutrition interventions have the potential to improve school attendance. Proper nutrition fosters better health; hence certain illnesses that would otherwise make pupils miss school due to sickness are avoided. Among schools with cooking demonstrations, children attend school better because they do not want to miss out on the prepared food (12). Additionally, since teacher-based nutrition interventions reach very many children at the same time, they are cost-effective.

\subsection{Conclusion}

There is an urgent call to make a case for teacher-based nutrition interventions in Sub- Saharan Africa schools. To break the rooted life cycle of malnutrition, there is a need to prioritise school-based nutrition interventions. All stakeholders, including teachers, school leaders, community leaders and parents, must come on board and commit to implementing and sustaining nutrition programs within the schools by redesigning the national formal and informal Primary school curriculums.

Adequate nutrition is an essential pillar of any thriving nation, especially in Sub- Saharan Africa. Teachers in schools have a potential platform upon which to influence learners' nutrition behaviours. By providing nutrition knowledge and skills to learners, they have the potential to reduce nutrition-related diseases in both the childhood stages and later in adulthood. Their understanding and recognition of this responsibility is a massive step in raising a healthy generation of African children. Teachers, however, need to be supported, encouraged and equipped with sound nutrition knowledge to facilitate a smooth nutrition education delivery process.

\subsection{Acknowledgements}

Appreciation is extended to Prof. Everd Maniple Bikaitwoha for his technical guidance during the conduct of the study. Additional appreciation is extended to Karen Helmy Nsamba for her moral and financial support. 


\section{References}

[1] World Health Organization. Essential nutrition actions: improving maternal, newborn, infant and young child health and nutrition [Internet]. World Health Organization; 2013 [cited 2021 Sep 21]. xi, 100 p. Available from: https://apps.who.int/iris/handle/10665/84409

[2] Ruel MT, Alderman H, Maternal and Child Nutrition Study Group. Nutrition-sensitive interventions and programmes: how can they help to accelerate progress in improving maternal and child nutrition? Lancet Lond Engl. 2013 Aug 10;382(9891):536-51. https://doi.org/10.1016/S01406736(13)60843-0.

[3] FAO. Regional Overview of Food Insecurity Africa. 2015;37.

[4] Bain LE, Awah PK, Geraldine N, Kindong NP, Sigal Y, Bernard N, et al. Malnutrition in Sub-Saharan Africa: burden, causes and prospects. Pan Afr Med J. 2013; 15:120. https://doi.org/10.11604/pamj.2013.15.120.2535.

[5] Ejaz MS, Latif N. Stunting and micronutrient deficiencies in malnourished children. JPMA J Pak Med Assoc. 2010 Jul;60(7):543-7.

[6] Fanzo J. The Nutrition Challenge in Sub-Saharan Africa. undefined [Internet]. 2012 [cited 2021 Sep 21]; Available from: https://www.semanticscholar.org/paper/The-Nutrition-Challenge-in-Sub-Saharan-Africa-Fanzo/51aefd4c04af42ebd9f15a562b258cf622088807

[7] Kulwa KBM, Verstraeten R, Bouckaert KP, Mamiro PS, Kolsteren PW, Lachat C. Effectiveness of a nutrition education package in improving feeding practices, dietary adequacy and growth of infants and young children in rural Tanzania: rationale, design and methods of a cluster randomised trial. BMC Public Health. 2014 Oct 16; 14:1077. https://doi.org/10.1186/1471-2458-14-1077.

[8] Ute I. Enhancing Academic Development through School Health Education and Promotion. Int J Educ Res Inf Sci. 2015 Jan 5;1(4):48.

[9] Androutsos O, Katsarou C, Payr A, Birnbaum J, Geyer C, Wildgruber A, et al. Designing and implementing teachers' training sessions in a kindergarten-based, family-involved intervention to prevent obesity in early childhood. The ToyBox-study. Obes Rev Off J Int Assoc Study Obes. 2014 Aug;15 Suppl 3:48-52. https://doi.org/10.1111/obr.12182.

[10] Glynn L. A critical appraisal tool for library and information research. Libr Hi Tech. 2006; https://doi.org/10.1108/07378830610692154.

[11] Jadad AR, Moore RA, Carroll D, Jenkinson C, Reynolds DJ, Gavaghan DJ, et al. Assessing the quality of reports of randomised clinical trials: is blinding necessary? Control Clin Trials. 1996 Feb;17(1):1-12. https://doi.org/10.1016/0197-2456(95)00134-4.

[12] Mbithe D, Kimiywe J, Waudo J, Orodho J. Promotion of nutrition education interventions in rural and urban primary schools in Machakos district, Kenya. undefined [Internet]. 2008 [cited 2021 Sep 21]; Available from: https://www.semanticscholar.org/paper/PROMOTION-OF-NUTRITIONEDUCATION-INTERVENTIONS-IN-Mbithe-Kimiywe/1a5fb87c63b6fa310568285d8c3939fd0251d809

[13] Eboh LO, Boye TE. Nutrition Knowledge and Food Choices of Primary School Pupils in the.

[14] Steyn NP, de Villiers A, Gwebushe N, Draper CE, Hill J, de Waal M, et al. Did HealthKick, a randomised controlled trial primary school nutrition intervention improve dietary quality of children in low-income settings in South Africa? BMC Public Health. 2015 Sep 23; 15:948. https://doi.org/10.1186/s12889-015-2282-4.

[15] Neervoort F, von Rosenstiel I, Bongers K, Demetriades M, Shacola M, Wolffers I. Effect of a school feeding programme on nutritional status and anaemia in an urban slum: a preliminary evaluation in Kenya. J Trop Pediatr. 2013 Jun;59(3):165-74. https://doi.org/10.1093/tropej/fms070.

[16] Oosthuizen D, Oldewage-Theron W, Napier C. The impact of a nutrition programme on the dietary intake patterns of primary school children. South Afr J Clin Nutr. 2011 Jan 1;24(2):75-81. https://doi.org/10.1080/16070658.2011.11734354.

[17] Tadayon Nabavi R. Bandura's Social Learning Theory \& Social Cognitive Learning Theory. 2012 Jan 1. https://doi.org/10.1002/9781118783764.wbieme0073. 